\title{
Rancang Bangun Aplikasi Fiqih Ibadah 4 Madzhab Berbasis Android
}

\author{
Sri Rahayu', Sukron Ma'mun², Iceu Sukmawati ${ }^{3}$ \\ Jurnal Algoritma \\ Sekolah Tinggi Teknologi Garut \\ J1. Mayor Syamsu No. 1 Jayaraga Garut 44151 Indonesia \\ Email : jurnal@itg.ac.id \\ ${ }^{1}$ srirahayu@itg.ac.id \\ 21606060@itg.ac.id \\ 3iceu.sukmawati@gmail.com
}

\begin{abstract}
Abstrak - Melihat perkembangan masa kini, masyarakat semakin antusias ikut serta mengembangkan teknologi yang semakin canggih, begitupun dalam hal ilmu kepesantrenan yang pada masa ini banyak masyarakat yang terprovokasi dengan berbedanya pemahaman dalam praktik beribadah yang benar, sehingga menyebabkan saling berjauhan satu sama lainnya, karena keterbatasan ilmu dan kurangnya minat dalam mencari ilmu tersebut. Solusinya yaitu perlu adanya sebuah media pembelajaran yang bisa menarik minat masyarakat untuk belajar memahami masalah Syari'at yang diikutinya terutama dibidang fikih supaya mudah dipahami dan menyenangkan. Penggunaan Multimedia dalam proses pembelajaran dinilai tepat dalam memberikan edukasi kepada masyarakat. Maka selanjutnya akan dirancang bangun sebuah aplikasi multimedia dalam memahami fiqih ubudiyah empat madzhab agar bisa lebih meminimalisir dalam perbedaaan pemahaman dalam beribadah terutama yang berkaitan dengan hukum syara'. Tujuan aplikasi ini adalah sebagai media pembelajaran fikih untuk masyarakat, menggunakan metodologi Multimedia Developnent Life Cycle (MDLC) dengan delapan tahapan yaitu, Identifikation, concept, design, material collecting, Assembly, testing, distribution dan publikation dengan hasil yang didapat berupa sebuah aplikasi multimedia pembelajaran fikih berbasis android yang lebih nyaman / mudah di gunakan berdasarkan pengujian sebesar $83 \%$ yang dapat berjalan di sistem operasi Android.
\end{abstract}

Kata Kunci - Android; Aplikasi Fiqih; Fiqih 4 Madzhab; Multimedia Development Life Cicle.

\section{PENDAHULUAN}

Fiqih merupakan salah satu cabang ilmu dengan pengkhususan dari ilmu lainnya karena tidak diketahui cabangnya, karenanya masalah yang muncul dapat berkembang dan bercabang [1]. Ketidaksesuaian persaudaraan antar sesame muslim pada masyarakat muslim terjadi karena khilafiyah madzhab dan khilafiyah cabang bidang fiqih lain. Sehingga,provokasi dikalangan masyarakat tidak seidkit yang ikut serta untuk memperkeruh suasanadisebabkan berbeda pendapat. Yang terjadi pada pengetahuan kebanyakan masyarakat adlah bahwa masalah perbedaan pendapat akan menjadikan suatu pertikaian dan perpecahan. Sehingga, orangorang cenderung untuk menghindari pembicaraan yang terkait dengan perbedaan pendapat keilmuan terutama bidang fiqih [2]. Padahal masalah yang mengandung khilafiyah bukan seharusnya dihindari, melainkan justru dipelajari dengan baik dan saksama agar ketidakharmonisan antar pemeluk agama Islam dapat dihindari. Khilafiyah (Perbedaan) adalah prinsip nilai yang dibutuhkan manusia dan akan membawa rahmat [3].

Sampai saat ini sarana yang digunakan masyarakat dalam memahami berbagai madzhab yaitu dengan menggunakan kutubusshalaf dalam bahasa arab yang cenderung tebal yakni seperti kitab Rohmatul Ummah Fi

Article History: $\quad$ Recivied Dec 18,2020 Revised Aug 9, $2021 \quad$ Accepted Aug 9, 2021 
Ikhtilafil Aimmah dengan menggunakan metode membaca, memahami dan membahas dari para guru ahli yang lainnya karena sampai saat ini kitab tersebut belum ada terjemahannya. Cara ini belum efektif mengingat tidak semua masyarakat berasal dari lingkungan berpendidikan saja melainkan dari berbagai kalangan yang kurang atau keterbatasan ilmu, tidak memiliki banyak waktu dan biaya untuk mencari dan mendatangi seorang ahli fiqih, sehingga perlu cara efektif dalam memahami dan mengetahui ajaran berbagai madzhab tersebut. Karena hal tersebut maka dibutuhkan media informasi yang membahas tentang ilmu fiqih 4 madzhab untuk bisa dijadikan bahan pembelajaran bagi semua kalangan sehingga perdebatan akan dapat di minimalisir.

Terdapat penelitian sebelumnya mengenai aplikasi terkait, diantaranya pada penelitian pertama [4] dimana penelitian tersebut bertujuan untuk memberikan penjelasan yang berkaitan dengan ilmu waris melalui android. Berbeda dengan aplikasi yang akan dibuat. Aplikasi yang akan dibuat berisi tentang fiqih yang membahas hal 'ubudiyah yang menjadi hal paling pokok untuk kehidupan sehari-hari. Penelitian kedua [5] penelitian tersebut menghasilkan sebuah aplikasi android berupa ebook sederhana dengan satu menu ditampilan utama berisi tentang daftar isi dari semua pembahasan . Berbeda dengan aplikasi yang akan dibuat ialah aplikasi android dengan tembahan beberapa menu dan fungsi lainnya seperti menu pengelompokkan beberapa pembahsan yang berkaitan dan menu search untuk memudahkan pengguna dalam mencari pembahsan yang dibutuhkan. Penelitian ketiga [6] berisi tentang pengetahuan ilmu fiqih dasar dari berbagi madzhab, kajian-kajian fiqhiyah secara global disajikan dalam sebuah aplikasi. Namun aplikasi yang dibuat selanjutnya ialah aplikasi yang berisi pembahasan fiqih ibadah secara menyeluruh terperinci dilengkapi sumber-sumber hukum yang terpercaya. Penelitian keempat [7] menghasilkan sebuah aplikasi android hadits arba'in dengan dilengkapi fitur scroll dan tombol lainnya tanpa tombol search. Dan penelitian kelima [8] menghasilkan sebuah aplikasi android yang didalamnya terdapat beberapa menu umum, namun seperti aplikasi lainya aplikasi ini belum memberikan menu search. Pada aplikasi yang akan dibuat ialah dengan menambahkan menu search untuk memudahkan dalam pencarian yang dibutuhkan.

\section{METODE PENELITIAN}

Multimedia Development Life Cycle (MDLC) merupakan metode yang digunakan, dimana metode ini adalah metode pengembangan multimedia yang memiliki tahapan konsep, perancangan aplikasi, pengumpulan material, pembuatan aplikasi, pengujian dan distribusi, MDLC Luther Sutopo yang telah dikutif oleh [9] [10] yang digambarkan dalam Gambar 1 WBS.

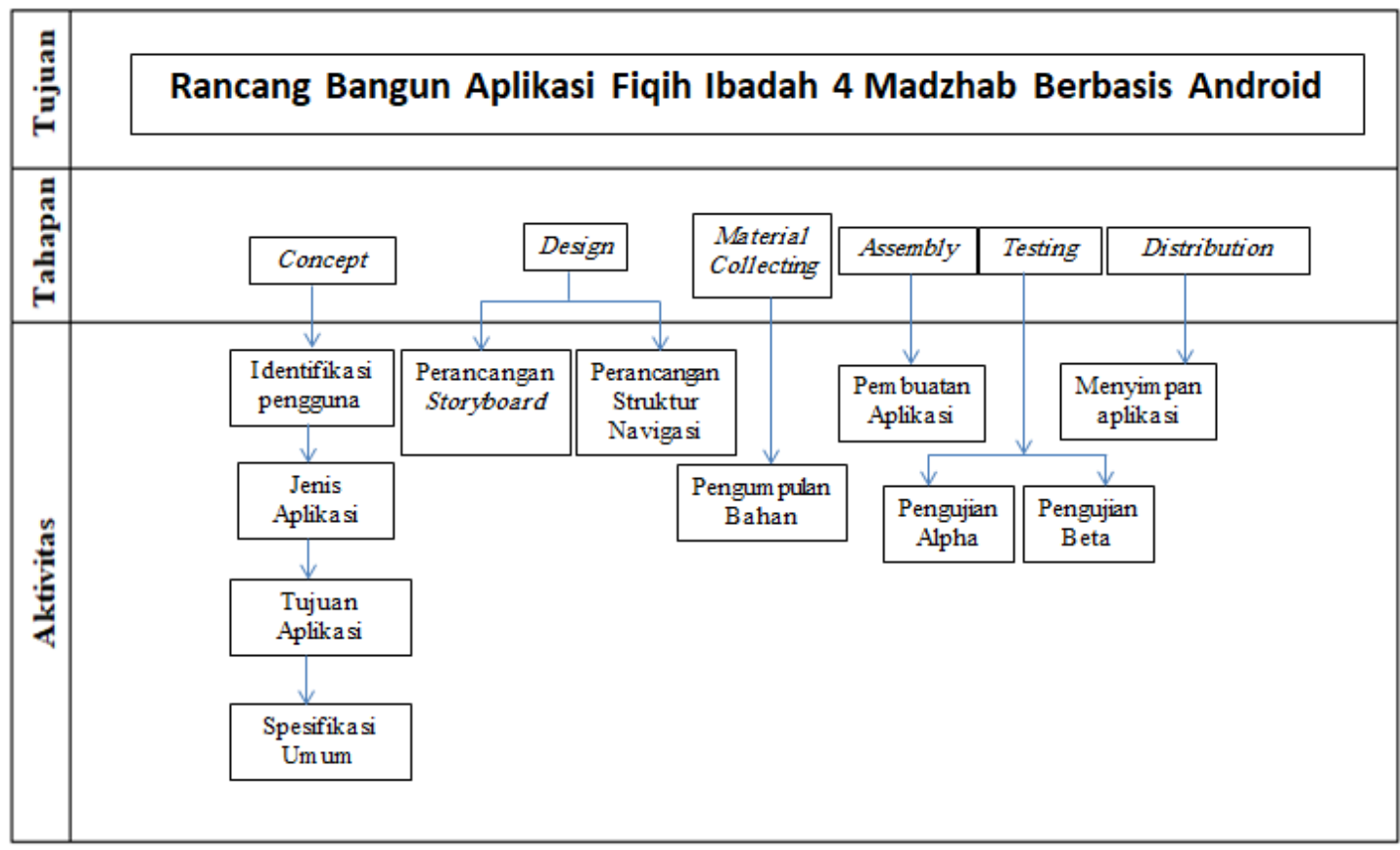


Gambar 1: Work Breakdown Structure

1. Konsep, merupakan tahapan yang dilakukan peneliti untuk menghasilkan kesenjangan dan rancangan aplikasi

2. Perancangan, merupakan tahapan merancang storyboard setiap scene dan merancang struktur navigasi dengan memasukan objek multimedia yang digunakan.

3. Pengumpulan Bahan, tahapan pengumpulan bahan seperti gambar, video dan bahan lainnya yang dibutuhkan untuk membuat aplikasi

4. Pembuatan, tahapan aplikasi mulai dibangun menggunakan bahan yang telah dikumpulkan.

5. Pengujian, etelah aplikasi dibuat, selanjutnya aplikasi dijalankan untuk diuji memeriksa aplikasi yang dibuat sudah berjalan seperti yang diharapkan.

6. Distribusi, etelah pengujian dilakukan tahapan selanjutnya program aplikasi yang telah diuji dan teruji sesuai yang diharapkan kemudian disimpan didalam mediapenyimpanan.

\section{HASIL DAN PEMBAHASAN}

\section{A. Hasil}

Hasil dari penelitian Rancang Bangun Aplikasi Fiqih Ibadah 4 Madzhab Berbasis Android menggunakan metodologi MDLC dengan 6 tahapan berikut:

\section{Concept}

Pada tahap Concept terdiri dari beberapa aktifitas yang dilakukan diantaranya identifikasi pengguna, jenis aplikasi, tujuan pembuatan aplikasi dan spesifikasi umum.

a. Identifikasi pengguna

Aplikasi ini diperuntukkan bagi seluruh masyarakat muslim secara umum dari mulai usia 9 tahun.

b. Jenis aplikasi

Jenis aplikasi yang dibuat adalah jenis aplikasi fiqih 4 madzhab yang dapat di akses melalui smartphone android dengan fitur-fitur utama yang sangat dibutuhkan.

c. Tujuan pembuatan aplikasi

Aplikasi fiqih ubudiyah 4 madzhab tersebut bertujuan untuk membantu masyarakat dalam mencari ilmu agama dengan mudah dan dapat diakses dimana saja.

d. Spesifikasi umum

Berdasarkan pada tujuan penelitian, maka dihasilkan spesifikasi umum tentang kebutuhan aplikasi yang akan dibuat berupa aplikasi media pembelajaran yang berisi tentang ilmu fiqih. Dimana aplikasi tersebut kemudian disajikan dalam deskripsi spesifikasi umum sebuah tabel 1.

Tabel 1: deskripsi spesifikasi umum aplikasi

\begin{tabular}{cll}
\hline No & Keterangan & \multicolumn{1}{c}{ Deskripsi } \\
\hline 1 & Judul & Aplikasi Fiqih 4 Madzhab berbasis android \\
\hline 2 & Pengguna & Masyarakat umum mulai usia 9 tahun \\
\hline 3 & Fitur & Menu Muqoddimah, menu materi, Menu kuis, menu Video praktik \\
\hline 4 & Gambar & Gambar backround, teks dan tombol \\
\hline 5 & Video & Video praktik yang langsung terhubung dengan youtube \\
\hline
\end{tabular}

\section{Design}

Design (Perancangan) ini adalah tahapan pembuatan mengenai arsitektur program, interface pada sebuah aplikasi dan kebutuhan material untuk program. Tahapan pembuatan ini akan dijadikan 
rancangandari setiap scenario atau kegiatan dari sebuah aplikasi dengan menggunakan storyboard singkat [11].

a. Perancangan storyboard

Perancangan ini digunakan untuk merancang dan mendeskripsikan aplikasi dari setiap scene. Juga menggambarkan rangkaian skenario atau kegiatan dari aplikasi. Berikut adalah gambaran tentang perancangan storyboard aplikasi yang disajikan dalam tabel 2.

Tabel 2: Ringkasan Perancangan Storyboard

\begin{tabular}{cl} 
Scene & \multicolumn{1}{c}{ Keterangan } \\
\hline Scene 1 & Halaman pembuka berupa gambar dan menu mulai \\
\hline Scene 2 & Halaman main cours (menu utama), menampilkan beberapa menu \\
\hline Scene 3 & Halaman materi bab thoharoh \\
\hline Scene 4 & Halaman materi bab Puasa \\
\hline Scene 5 & Halaman materi bab zakat \\
\hline Scene 6 & Halaman materi bab Jenazah \\
\hline Scene 7 & Halaman kuis \\
\hline Scene 8 & Halaman Skor \\
\hline Scene 9 & Halaman sub menu pada menu video praktik \\
\hline
\end{tabular}

b. Perancangan Struktur Navigasi

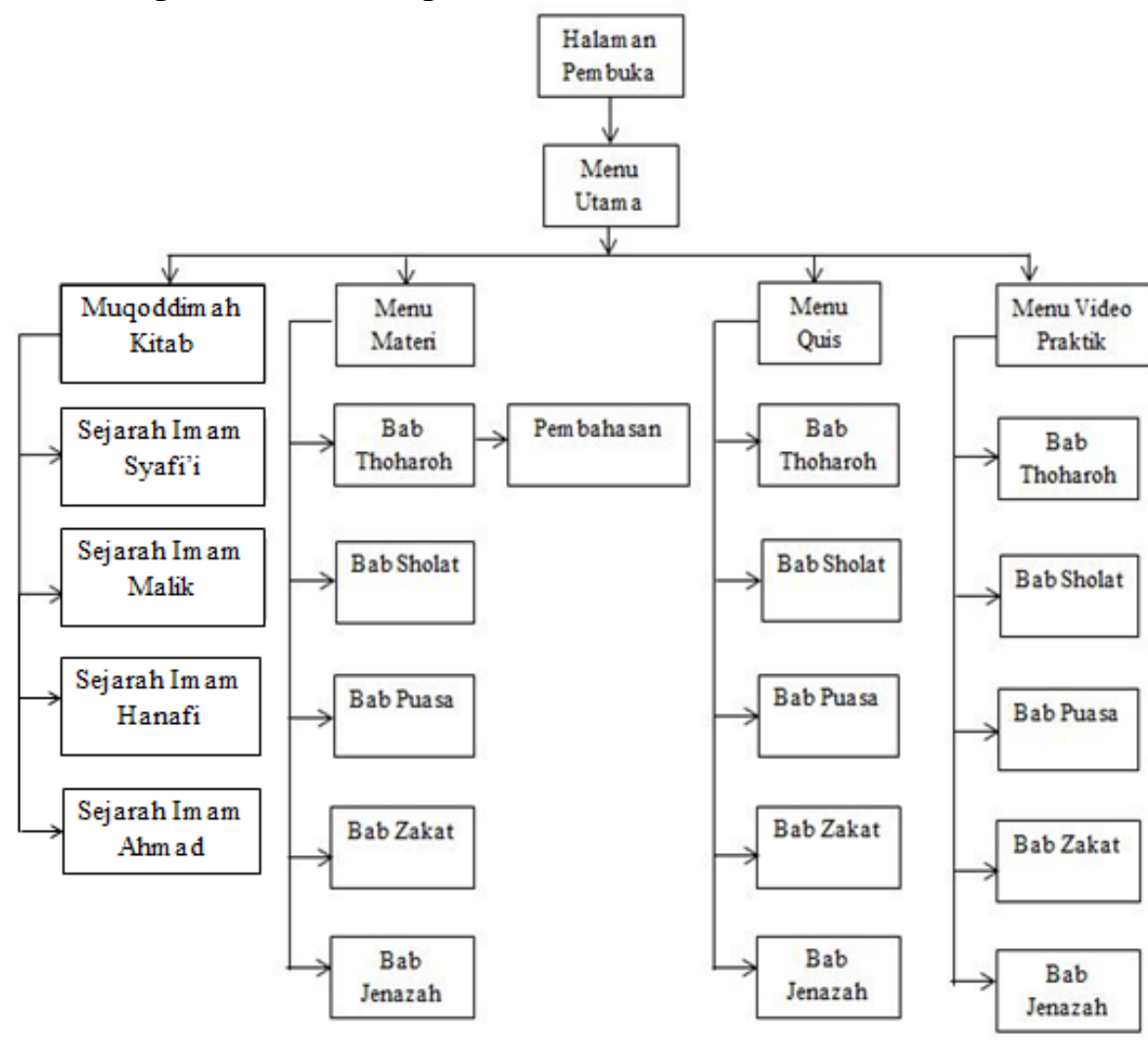

Gambar 3: Perancangan Struktur navigasi

\section{Pengumpulan Material}

Pada tahapan ini, materi terkait yang ada pada aplikasi didapatkan dari buku referensi fiqih 5 madzhab dan mencari sumber lainnya dari internet. material pembuatan sebuah aplikasi yang dikumpulkan 
berupa icon-icon ficture seperti gambar-gambar yang akan digunakan di beberapa tampilan di aplikasi. Selanjutnya kebutuhan pembuatan aplikasi juga dibutuhkan perangkat keras dan perangkat lunak. Prangkat keras yang dibutuhkan diantaranya terlihat pada tabel 3 dan 4

Tabel 3: Kebutuhan Perangkat Keras

\begin{tabular}{ll}
\hline \multicolumn{1}{c}{ Perangkat } & \multicolumn{1}{c}{ Spesifikasi } \\
\hline Laptop & LENOVO Raedon R5, dengan RAM 4 GB 5 compute Cores $2 C+3 G 3,10$ \\
& GHz \\
\hline Handphone & Luna G55, Ram 4GB, versi android 6.0" \\
\hline
\end{tabular}

Tabel 4: Kebutuhan Perangkat Lunak

\begin{tabular}{|c|c|c|}
\hline No. & Aplikasi & Deskripsi \\
\hline 1 & Whimsical & Pembuatan wireframe \\
\hline 2 & Figma & Pembuatan prototype \\
\hline 3 & Photoshop & Pembuatan dan edit icon \\
\hline 4 & Android Studio & Menulis kode \\
\hline
\end{tabular}

\section{Assembly}

Tahapan ini merupakan tahapan pembuatan aplikasi, dimana pembuatan tersebut berdasar pada tahapan perancangan aplikasi. Seluruh kebutuhan material yang telah dikumpulkan kemudian selanjutnya diinput atau dimasukan kedalam sotfwere seperti android studio untuk disusun. Berikut proses pembuatan dan implementasi gambar dan teks penyusunan material yang akan digunakan pada aplikasi dan hasil dari aplikasi fiqih 4 madzhab.

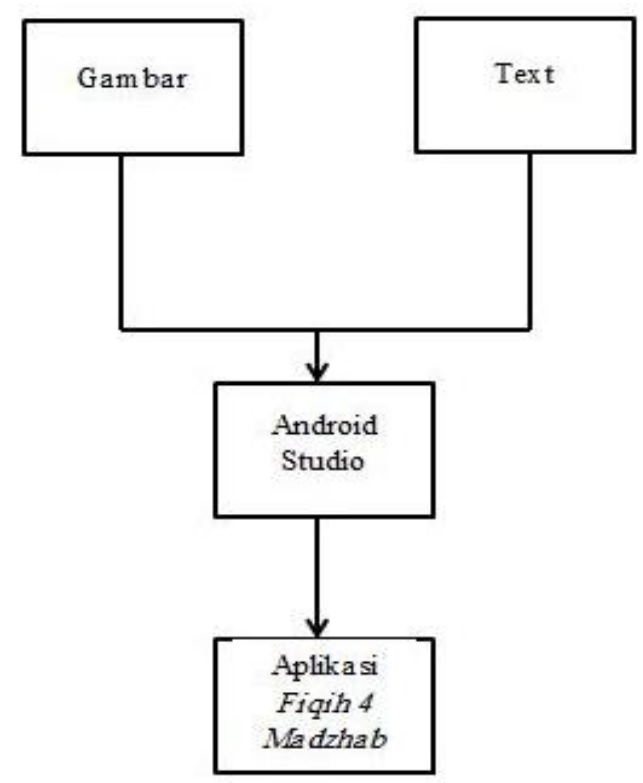

Gambar 4: Proses pembuatan aplikasi 


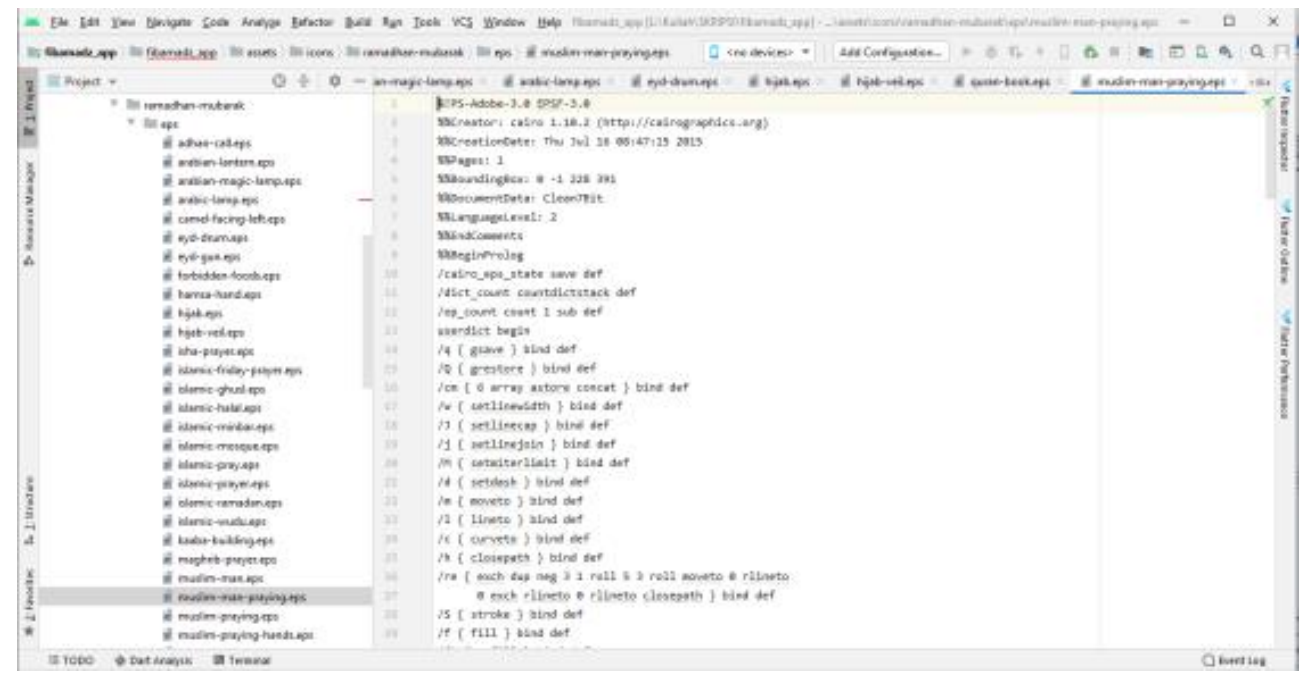

Gambar 5: Proses Implementasi Gambar

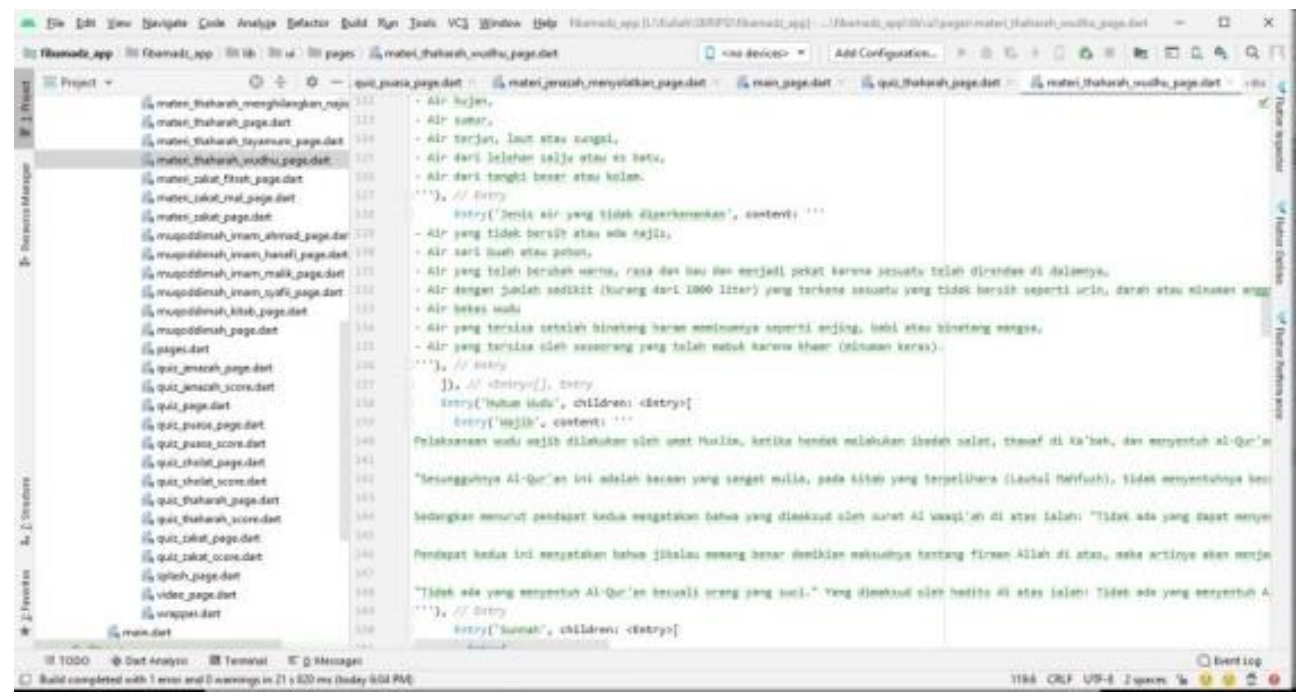

Gambar 6: Proses Implementasi Teks

\section{Pengujian}

Pada tahapan pengujian berikut, terdapat dua tahapan yang dilakukan dalam pengujian aplikasi fiqih ibadah 4 madzhab berbasis android yaitu alpha testing (pengujian alpha) dan beta testing (pengujian beta) [12]

a. Pengujian Alpha (alpha testing)

Tabel 3: Pengujian Alpha

\begin{tabular}{ccccc}
\hline No & Kelas uji & Keterangan uji & $\begin{array}{c}\text { Jenis } \\
\text { pengujian }\end{array}$ & Hasil uji \\
\hline $\mathbf{1 .}$ & $\begin{array}{c}\text { Proses } \\
\text { penginstalan }\end{array}$ & $\begin{array}{c}\text { Melakukan pemasangan aplikasi pada } \\
\text { android device }\end{array}$ & Black Box & Sukses \\
\hline 2. & Pembuka & $\begin{array}{c}\text { Aplikasi tampil, Logo Aplikasi, Nama } \\
\text { aplikasi dan tombol start }\end{array}$ & Black Box & Sukses \\
\hline
\end{tabular}




\begin{tabular}{|c|c|c|c|c|}
\hline No & Kelas uji & Keterangan uji & $\begin{array}{c}\text { Jenis } \\
\text { pengujian }\end{array}$ & Hasil uji \\
\hline \multirow[t]{4}{*}{3.} & Halaman Menu & Muqoddimah & Black Box & Sukses \\
\hline & & Materi & Black Box & Sukses \\
\hline & & Kuis & Black Box & Sukses \\
\hline & & Video Praktik & Black Box & Sukses \\
\hline \multirow[t]{5}{*}{4.} & Halaman & Muqoddimah kitab & Black Box & Sukses \\
\hline & submenu & Sejarah Imam syafi' $i$ & Black Box & Sukses \\
\hline & muqoddimah & Sejarah Imam Hanfi & Black Box & Sukses \\
\hline & & Sejarah Imam Maliki & Black Box & Sukses \\
\hline & & Sejarah Imam Ahmad & Black Box & Sukses \\
\hline \multirow[t]{5}{*}{5.} & Halaman sub & Thoharoh & Black Box & Sukses \\
\hline & menu materi & Sholat & Black Box & Sukses \\
\hline & & Puasa & Black Box & Sukses \\
\hline & & Zakat & Black Box & Sukses \\
\hline & & Jenazah & Black Box & Sukses \\
\hline 6. & $\begin{array}{l}\text { Halaman menu } \\
\text { Kuis }\end{array}$ & Pertanyaan dan pilihan jawaban & Black Box & Sukses \\
\hline 7. & $\begin{array}{l}\text { Halaman } \\
\text { pernyataan } \\
\text { persetujuan }\end{array}$ & Menampilkan tombol yes dan no & Black Box & Sukses \\
\hline 8. & Halaman skor & $\begin{array}{l}\text { Menampilkan nilai yang didapat pada } \\
\text { setiap jawaban soal }\end{array}$ & Black Box & Sukses \\
\hline 9. & $\begin{array}{l}\text { Halaman menu } \\
\text { Video Praktik }\end{array}$ & Menu kategori video youtube & Black box & sukses \\
\hline
\end{tabular}

b. Pengujian beta (beta testing)

Tabel 4: Hasil kuisioner kenyamanan dan kelayakan aplikasi

\begin{tabular}{|c|c|c|c|c|c|c|c|c|}
\hline \multirow{2}{*}{ No } & \multirow{2}{*}{ Pertanyaan } & \multicolumn{5}{|c|}{ Jawaban } & \multirow{2}{*}{ Total Responden } & \multirow{2}{*}{ Hasil (\%) } \\
\hline & & 1 & 2 & 3 & 4 & 5 & & \\
\hline 1 & $\begin{array}{l}\text { Apakah diperlukan sebuah aplikasi } \\
\text { Fiqih ibadah dari } 4 \text { madzhab } \\
\text { berbasis android saat ini? }\end{array}$ & & & & 5 & 25 & 30 & $96 \%$ \\
\hline 2 & $\begin{array}{l}\text { Apakah view pada background } \\
\text { sudah sesuai dengan judul dan tema } \\
\text { pada aplikasi tersebut? }\end{array}$ & & & & 10 & 20 & 30 & $93 \%$ \\
\hline 3 & $\begin{array}{l}\text { Apakah isi materi sudah sesuai } \\
\text { dengan judul aplikasi? }\end{array}$ & & & 5 & 10 & 15 & 30 & $86 \%$ \\
\hline 4 & $\begin{array}{l}\text { Apakah desain tombol navigasi } \\
\text { pada aplikasi ini sudah sesuai? }\end{array}$ & & & 5 & 15 & 10 & 30 & $83 \%$ \\
\hline 5 & $\begin{array}{l}\text { Apakah materi yang disampaikan } \\
\text { dapat membantu untuk proses } \\
\text { belajar masyarakat? }\end{array}$ & & & 6 & 10 & 14 & 30 & $85 \%$ \\
\hline 6 & $\begin{array}{l}\text { Apakah gambar pada aplikasi ini } \\
\text { sudah sesuai dengan isi materi ? }\end{array}$ & & & 3 & 12 & 15 & 30 & $88 \%$ \\
\hline 7 & $\begin{array}{l}\text { Apakah pemilihan jenis dan ukuran } \\
\text { teks sudah sesuai pada? }\end{array}$ & & & 7 & 10 & 13 & 30 & $84 \%$ \\
\hline 8 & $\begin{array}{l}\text { Apakah dalam penggunaan aplikasi } \\
\text { ini mudah? }\end{array}$ & & & 4 & 6 & 20 & 30 & $90 \%$ \\
\hline
\end{tabular}




\begin{tabular}{|c|c|c|c|c|c|c|c|c|}
\hline \multirow{2}{*}{ No } & \multirow{2}{*}{ Pertanyaan } & \multicolumn{5}{|c|}{ Jawaban } & \multirow{2}{*}{ Total Responden } & \multirow{2}{*}{ Hasil (\%) } \\
\hline & & 1 & 2 & 3 & 4 & 5 & & \\
\hline 9 & $\begin{array}{l}\text { Apakah materi yang disajikan dapat } \\
\text { dan mudah difahami? }\end{array}$ & & & 2 & 8 & 20 & 30 & $92 \%$ \\
\hline 10 & $\begin{array}{l}\text { Apakah fitur kuis membantu dalam } \\
\text { pemahaman materi ? }\end{array}$ & & & 4 & 12 & 14 & 30 & $86 \%$ \\
\hline
\end{tabular}

Dengan menggunakan rumus grand mean, berdasarkan dari hasil kuesioner pada tabel 4. dapat ditarik kesimpulan penentuan nilai respon pengguna untuk kenyamanan penggunaan, berikut perhitungannya:

Keterangan :

$$
G M=\frac{\sum \mathrm{X}}{n}=\frac{96+93+86+83+85+88+84+90+92+86}{10}=88,3
$$

$$
\begin{array}{ll}
\mathrm{GM} & \text { : Grand Mean } \\
\Sigma \mathrm{X} & \text { : Jumlah rata-rata semua soal kuisioner } \\
\mathrm{n} & \text { : Jurnal soal }
\end{array}
$$

\section{Distribution}

Pada tahap selanjutnya yaitu tahapan akhir dari metode yang digunakan dari semua penelitian telah selesai, kemudian aplikasi disimpan pada perangkat komputer untuk selanjutnya di publikasikan.

\section{B. Pembahasan}

Pada penelitian ini yaitu merancang bangun aplikasi fiqih ibadah empat madzhab berbasis android tujuannya untuk memberikan pengetahun dengan mempermudah dalam mengakses pembahasan yang dicari.

\section{Jawaban pertanyaan penelitian}

Berdasarkan pada pertanyaan tentang Bagaimana menarik minat masyarakat dalam mempelajari fiqih lintas madzhab, Bagaimana merancang aplikasi pembelajaran fiqih yang praktis tanpa harus pergi ke ahli fiqih dan Bagaimana agar aplikasi dapat lebih efektif dan mudah untuk digunakan, maka:

a. Dengan adanya aplikasi fiqih ibadah, masyarakat tidak lagi repot belajar secara konvensional

b. Dengan menggunakan softwere android studio dapat menjadikan file .apk dapat menyediakan aplikasi fiqih ibadah 4 madzhab yang didalamnya berisi materi materi terkait seperti thoharoh, sholat, puasa zakat dan jenazah.

c. Aplikasi yang menyediakan tombol navigasi memudahkan pengguna dalam mengakses materi yang diinginkan, juga tersedianya menu pencarian pada beberapa halaman utama.

\section{KESIMPULAN}

Berdasarkan pembahasan dan hasil yang telah dipaparkan dan diperoleh, maka dapat ditarik kesimpulan sebagai berikut:

1. Aplikasi Fiqih Ibadah Empat Madzhab Berbasis Android yang dibangun menyajikan materi-materi yang berkaitan dengan fiqih ibadah dari berbagai madzhab disertai video praktik.

2. Aplikasi Fiqih Ibadah Empat Madzhab Berbasis Android menyediakan fitur kuis untuk dijadikan bahan dalam mengevaluasi sejauh mana pengetahuan dan pemahaman pengguna dalam memahami materimateri yang disajikan. 


\section{DAFTAR PUSTAKA}

[1] Muhammd Jawad Mughniyah, Al-Fiqh 'Ala Al-Madhahib Al-Khamsah, Edisi Leng. Jakarta: Penerbit Lentera, 2011.

[2] Sarwat, "Fiqih Ikhtilaf," Yayasan Darul Al Ulum Al Islam., vol. 2, p. 1, 2007.

[3] R. A. H Baharun, "Pendidikan Multikultural Dalam Menanggulangi narasi Islamimisme di Indonesia," J. Pendidik. Agama Islam, vol. 05, no. Vol. 05 no. 02 (2017), p. 3, 2017.

[4] Fitri Ariyanti, "Aplikasi Faraid Menurut Fiqih Islam Berbasis Android,” vol. 08, pp. 1-6, 2015.

[5] Ipan Rifai, "Rancang Bangun Aplikasi Android Kitab Bulughul Maram Menggunakan Eclipse," J. ICT Learn., vol. 02, p. 21, 2016.

[6] R. P. Novita Kusumadewi, M. Hasan Muiz Abdai, "ABFI (Aplikasi Belajar Fiqih Ikhtilaf) PENGEMBANGAN APLIKASI FIQIH PERBANDINGAN MAZHAB BERBASIS ANDROID,” $J$. Islam Nusant., vol. 02, p. 2, 2018.

[7] Sri Rahayu, "Perancangan Aplikasi Hadits Arba'in An-Nawawiyah Menggunakan Sistem Multimedia," J. Algoritm., 2017.

[8] N. D. U SimalangoA Huda, "Rancang Bangun Aplikasi Multimedia Interaktif Mobile Learning," $J$. Vocat., p. 2, 2018.

[9] S. R. Ahmad Maulana, "Rancang Bangun Aplikasi Panduan Cara Membuat Identitas Diri Untuk Penyandang Autis," J. Algoritm., vol. 17, p. 2, 2020.

[10] D. Heryanto, A. Sutedi, and R. Cahyana, "The proposed information system design to improve new students,” J. Phys. Conf. Ser., vol. 1402, no. 2, p. 022080, 2019.

[11] A. R. Hilman Septian, Eka Wahyu Hidayat, "Aplikasi Pengenalan Bahasa Arabdan Inggrisuntuk AnakAnak Berbasis Android," JOIN, vol. 2, p. 3, 2018.

[12] N. H. Wahyu Arya Pambudi, Didi Juardi, "Aplikasi Edukasi Mengenal Makanan Khas Karawang Untuk Raudhatul Athfal," p. 7, 2019. 